\title{
PROJETO DE LAYOUT DE BIBLIOTECA ASSISTIDO POR FERRAMENTA DE SOFTWARE PARA CRIAÇÃO DE ARRANJO FíSICO EM 3D: ESTUDO APLICADO À BIBLIOTECA DA FACULDADE IDEZ
}

\section{PROYECTO DE LAYOUT DE BIBLIOTECA ASISTIDO POR HERRAMIENTA DE SOFTWARE PARA CREACIÓN DE ARREGLO FÍSICO EM 3D: ESTUDIO APLICADO A LA BIBLIOTECA DE LA FACULTAD IDEZ}

Sanderli José da Silva Segundo - sanderbrown1@hotmail.com Graduando do curso de Biblioteconomia da Universidade Federal da

Paraíba (UFPB).

Wagner Junqueira de Araújo - wagnerjunqueira.araujo@gmail.com Doutor em Ciência da Informação pela Universidade de Brasília (UnB). Docente do Departamento de Ciência da Informação da Universidade Federal da Paraíba (UFPB).

Wendy-Anna Albuquerque Lopes - wendyufpb@gmail.com Graduanda do curso de Biblioteconomia da Universidade Federal da

Paraíba (UFPB).

\section{RESUMO}

Introdução: Projetar uma biblioteca consiste em concentrar esforços para criar ou aprimorar atividades que estejam de acordo com a função e objetivos da mesma e da instituição a qual está subordinada. Regularmente os responsáveis por diferentes tipos de bibliotecas se deparam com o problema de gestão do seu espaço físico. O estudo do layout proporciona experimentar novas formas e permite modificações de ambientação com o intuito de buscar os requisitos citados. Contudo fazer isso em um ambiente real, nem sempre é possível, nestes casos uma ferramenta que permita ao bibliotecário projetar, promover alterações e visualizar os resultados em formatos 3D é de grande auxilio. 
Sanderli José da Silva Segundo; Wagner Junqueira de Araújo; Wendy-Anna Albuquerque Lopes

Projeto de layout de biblioteca assistido por ferramenta de software para criação de arranjo físico em 3D: estudo aplicado à biblioteca da faculdade Idez

Objetivo: Estudar o arranjo físico de bibliotecas sob a ótica de OS\&M usando ferramentas 3D.

Metodologia: Apresenta um estudo de caso na biblioteca da Faculdade iDEZ, localizada em João Pessoa - PB, onde foi aplicado os princípios da disciplina de Organização, Sistemas e Métodos (OS\&M) para arranjo físico (layout) utilizando uma ferramenta de software livre para auxiliar projetos em terceira dimensão.

Resultados: São indicadas e discutidas as motivações que levam um profissional de informação a ter que gerenciar seu espaço físico e as barreiras encontradas. O resultado obtido na avaliação indicou o Sweet Home 3D como ferramenta com melhor pontuação.

Conclusões: A proposta de projeto resultante do estudo de caso, facilitou a visualização das mudanças, sendo aceita e implementada pelos gestores da biblioteca.

Palavras-chave: Tecnologia da informação e comunicação. Projeto de biblioteca. Software livre. Arranjo físico. Layout 3D.

\section{INTRODUÇÃO}

O paradigma acesso/disseminação, efervescente conceito da sociedade pósmoderna, está ligado ao fim da $2^{a}$ Guerra Mundial (1945), onde dois grandes fenômenos tomaram forma: Globalização e Explosão Bibliográfica. O primeiro termo aqui citado quebrou barreiras de espaço e tempo, esticando a tenda comercial dos países desenvolvidos, denominados de Primeiro Mundo. Importante arma econômica do capitalismo, a globalização investiu no aprimoramento, criação e barateamento das Tecnologias da Informação e Comunicação (TIC's). O segundo termo trouxe preocupação para os profissionais da informação, as bibliotecas acostumadas com o ritmo lento em que se publicavam novas obras, ficaram de mãos atadas quando tentaram acompanhar essa corrida informacional.

Como organização a biblioteca precisou adaptar-se a essas tendências sociais, de guardiã passou a despenseira do conhecimento, e no século XXI já não imaginamos outro adjetivo que não remeta essa ideia. Vista pelos mais entusiastas como empresa, ela deve estar sempre passando por análises para mostrar se seus objetivos estão sendo cumpridos. O improviso nem sempre acha espaço para atuar nas organizações, claro que em alguns momentos ele será bem vindo e poderá inclusive dar início a uma boa estratégia, todavia, até o ato de "improvisar" tem que estar sob um planejamento atuante e atento para tirar proveito das súbitas ações. Planejar segundo Ferreira (1983), "É um processo, e como todo processo é ininterrupto", ou seja, não basta agrupar recursos, traçar metas e ações, o 
Sanderli José da Silva Segundo; Wagner Junqueira de Araújo; Wendy-Anna Albuquerque Lopes

Projeto de layout de biblioteca assistido por ferramenta de software para criação de arranjo físico em 3D: estudo aplicado à biblioteca da faculdade Idez

administrador precisa avaliar sempre que possível a eficácia dos planos adotados. Isso requer algumas ferramentas capazes de orientar o profissional na criação ou aprimoramento do planejamento. O Arranjo Físico é capaz de indicar quais pontos fortes e fracos estão, respectivamente, beneficiando e prejudicando a organização. Regularmente os responsáveis por diferentes tipos de bibliotecas se deparam com o problema de gestão do seu espaço físico.

Neste contexto será que a visualização de um projeto de layout em terceira dimensão facilitaria os gestores no entendimento de uma proposta para adequação do espaço físico? Este artigo apresenta os resultados de trabalho experimental desenvolvido por meio de um estudo de caso na biblioteca da Faculdade iDEZ, localizada em João Pessoa - PB, onde foi aplicado os princípios da disciplina de Organização, Sistemas e Métodos (OS\&M) para arranjo físico (layout) utilizando uma ferramenta de software livre para auxiliar projetos em terceira dimensão. O objetivo geral foi estudar o arranjo fisco de bibliotecas sob a ótica de OS\&M usando ferramentas 3D. Os objetivos específicos foram: estudar o fluxo de informação e trabalho de uma organização. Identificar situação favorável a usuários e visitantes. Selecionar ferramenta de software para análise de layout em formato 3D. Indicar uma proposta de melhoria na utilização da área em estudo. São indicadas e discutidas as motivações que levam um profissional de informação a ter que gerenciar seu espaço físico e as barreiras encontradas.

\section{PROJETOS DE BIBLIOTECAS}

Projetar uma biblioteca consiste em concentrar esforços para criar ou aprimorar atividades que estejam de acordo com a função e objetivos da mesma e da instituição a qual está subordinada. O projeto ajuda a evitar danos futuros e gasto desnecessário, facilita na descrição e aperfeiçoamento dos produtos e serviços oferecidos e ainda permite que o bibliotecário revise as metas traçadas e determine se elas continuam suprindo às necessidades dos usuários. Fayol (1916), afirma que administrar é "[...] prever, organizar, comandar, coordenar e controlar." Partindo desse princípio, planejar e executar são ações interdependentes, indispensáveis para conquistar metas e objetivos. O planejamento estratégico possibilita idealizar e 
Sanderli José da Silva Segundo; Wagner Junqueira de Araújo; Wendy-Anna Albuquerque Lopes

Projeto de layout de biblioteca assistido por ferramenta de software para criação de arranjo físico em 3D: estudo aplicado à biblioteca da faculdade Idez

experimentar aprimoramentos, modificações e implantações de novas atividades na biblioteca, sua tomada de decisão é baseada na reflexão, maturação e crítica.

O planejamento estratégico possibilita um diagnóstico preciso da realidade, favorecendo a participação que é fundamental na implementação de ações que contribuem para a melhoria da qualidade. Constitui um excelente recurso para a tomada de decisões, programação, controle e avaliação de atividades (NASCIMENTO et al., 2000).

Para os mais desavisados, planejar o ambiente de uma biblioteca pode parecer fácil. Segundo Maciel (2000), "seja qual for a categoria e a realidade em que se enquadre, a biblioteca deve ser vista como uma organização, como uma empresa [...] com resultados programados e avaliados constantemente." A partir desse conceito é possível entender o bibliotecário como gestor da informação e do ambiente que ele transita. O que inclui gerenciamento de coleções, seleção, aquisição e desbastamento de materiais, gestão de pessoas e de instalações, processos administrativos que visam detectar pontos fortes $e$ fracos no aproveitamento do espaço físico. As necessidades de gerenciamento do espaço físico em ambientes como bibliotecas, demandam uma atenção toda especial do gestor. Projetos de layout permitem que ele avalie a eficiência das atividades exercidas na organização e as reconfigure sempre que necessário organizando a disposição de móveis, objetos e atividades. O arranjo físico pode abordar questões como:

- Recepção: ao entrar no ambiente, é necessário que um funcionário esteja bem localizado para dar as boas vindas, oferecer ajuda e orientar o usuário;

- Circulação: os serviços e produtos destinados ao público devem ter fácil acesso e possuírem um bom espaço de circulação;

- Balcão de empréstimos, renovações, devoluções: precisa estar o mais próximo possível da entrada/saída, evitar acúmulo de usuários e exercer função fiscalizadora coibindo possíveis subtrações do acervo;

- Mesa/Sala do Bibliotecário: precisa estar localizada de forma que possa visualizar o andamento de todos os setores e fluxos da Biblioteca e 
Sanderli José da Silva Segundo; Wagner Junqueira de Araújo; Wendy-Anna Albuquerque Lopes

Projeto de layout de biblioteca assistido por ferramenta de software para criação de arranjo físico em 3D: estudo aplicado à biblioteca da faculdade Idez

também privar os demais das informações gerenciais produzidas pelo bibliotecário;

- Acervo: É necessário que esteja às vistas de um ou mais funcionários, tanto para ajudar os usuários na procura de documentos quanto para evitar vandalismos e subtrações, e que siga uma sequência lógica num espaço delimitado;

- Computadores: Sejam os que oferecem consultas ao acervo ou acesso à internet, o posicionamento ideal é perto do acervo, porque são ferramentas indispensáveis no complemento do conhecimento físico organizado e no suporte a estudos e pesquisas;

- Mesas de estudos individuais ou em grupos: Não podem estar posicionadas entre as estantes, ou atrás delas. O ideal é que estejam em lugares relativamente distantes do acervo, sem barreiras visuais (colunas, armários e etc.), facilitando a identificação dos usuários e de documentos que possivelmente eles tenham tomado emprestado para consultar.

O usuário quando busca por informação, se desestimula ao dar inúmeras voltas para encontrar o que quer. Imagine se em uma determinada unidade, onde a mesa de empréstimos esteja localizada no terceiro piso, o acervo no primeiro, os acentos no segundo e assim por diante, a disposição dos serviços imputaria ao usuário peregrinação sem fim. Devemos entender a biblioteca como um ponto de referência na organização, para isso além dos serviços informacionais, ela deve oferecer um espaço que promova acesso e troca de informações. As funções e serviços básicos de uma biblioteca, seja ela grande ou pequena, necessitam considerar itens como os fluxos informacionais, conforto, acessibilidade e segurança de suas atividades.

O estudo do layout proporciona experimentar novas formas e permite modificações de ambientação com o intuito de buscar os requisitos citados. Contudo fazer isso em um ambiente real, nem sempre é possível, nestes casos uma ferramenta que permita ao bibliotecário, projetar, promover alterações e visualizar os resultados em formatos $3 \mathrm{D}$ é de grande auxilio. Porém quando se trata de trabalhar 0 
Sanderli José da Silva Segundo; Wagner Junqueira de Araújo; Wendy-Anna Albuquerque Lopes

Projeto de layout de biblioteca assistido por ferramenta de software para criação de arranjo físico em 3D: estudo aplicado à biblioteca da faculdade Idez

arranjo físico (layout), qualquer que seja a organização, alguns princípios devem ser observados conforme indicado no quadro 1:

Quadro 1 - Princípios de layout

\begin{tabular}{|l|c|}
\hline \multicolumn{1}{|c|}{ Princípios } & Autor \\
\hline $\begin{array}{l}\text { O trabalho deve seguir um fluxo contínuo e para frente, o } \\
\text { mais próximo possível da linha reta; }\end{array}$ & $\begin{array}{c}\text { Cury (2000) } \\
\text { Oliveira (2006) }\end{array}$ \\
\hline $\begin{array}{l}\text { Os móveis e os equipamentos devem ser arrumados em } \\
\text { simetria e em linha reta tanto quanto possível; }\end{array}$ & $\begin{array}{c}\text { Cury (2000); Araújo (2001); } \\
\text { Oliveira (2006). }\end{array}$ \\
\hline $\begin{array}{l}\text { Os padrões de espaço devem ser adequados às } \\
\text { necessidades de trabalho e de conforto dos empregados; }\end{array}$ & $\begin{array}{c}\text { Cury (2000); Araújo (2001); } \\
\text { Oliveira (2006). }\end{array}$ \\
\hline $\begin{array}{l}\text { Os móveis e os equipamentos de tamanho uniforme } \\
\text { permitem maior flexibilidade e aparência mais uniforme; }\end{array}$ & $\begin{array}{c}\text { Cury (2000); } \\
\text { Araújo (2001); }\end{array}$ \\
Oliveira (2006). \\
\hline $\begin{array}{l}\text { Os vãos de circulação devem ser suficientemente } \\
\text { exemplos, evitando que as pessoas esbarrem no } \\
\text { mobiliário. Portanto, é importante a existência de um } \\
\text { corredor, sem obstrução, desde a área das mesas até os } \\
\text { bebedouros, sanitários, saídas etc., inclusive por medida } \\
\text { de segurança. }\end{array}$ & $\begin{array}{c}\text { Cury (2000); } \\
\text { Oliveira (2006). }\end{array}$ \\
\hline
\end{tabular}

Fonte: Adaptado de Cury (2000), Araújo (2001) e Oliveira (2006).

Como fazer isso? Cury (2000), Araújo (2001) e Oliveira (2006), indicam que uma das maneiras é trabalhar a questão do arranjo físico. O Profissional da informação, além de gerenciar recursos informacionais de sua instituição/trabalho/empresa, em muitos casos se depara com a necessidade de gerenciar o espaço físico para a instalação da biblioteca, do seu arquivo, de sua unidade de informação. Neste cenário, quais ferramentas podem auxiliar nesta atividade, sem que o bibliotecário tenha que procurar um engenheiro ou arquiteto?

Hoje é simples enumerar diversas ferramentas de software que suprem tal necessidade. Porém a questão não se restringe somente em qual usar, mas como usar e, principalmente, quanto custa. Barreiras encontradas na alocação de recursos de pessoal, recursos financeiros, treinamento e políticas internas de segurança da informação - sobretudo nas instituições públicas, dificultam a utilização de softwares de licenças pagas que auxiliem, por exemplo, a criação de um simples layout. Esses obstáculos direcionam o profissional da informação a encontrar nas ferramentas com 
Sanderli José da Silva Segundo; Wagner Junqueira de Araújo; Wendy-Anna Albuquerque Lopes

Projeto de layout de biblioteca assistido por ferramenta de software para criação de arranjo físico em 3D: estudo aplicado à biblioteca da faculdade Idez

licenças GPL (GNU GENERAL PUBLIC LICENSE, 2011), conhecidas como "Software Livre", uma alternativa para transpor estas barreiras.

\section{SOFTWARE LIVRE: ALTERNATIVAS PARA FERRAMENTAS DE SOFTWARE}

O conceito "Software Livre" foi criado por Richard Stallman, na intenção de trazer liberdade de manuseio, manipulação, aperfeiçoamento, criação e disseminação aos usuários de programas de computadores. É um movimento político-social, que levanta a bandeira da seguinte missão: não aprisionar o conhecimento científico, que deve ser livre e contribuir para a evolução da humanidade. Sinteticamente, a corrente defende o término do controle de uso. Essa idéia ganhou adeptos e Stallman, em 1983, elaborou uma licença para esse tipo de software, chamada GPL (General Public License), que se baseia em quatro liberdades, a de executar, estudar, redistribuir e aperfeiçoar o programa; Liberdades que formaram um conceito, chamado "Copleff", pregando o compartilhamento da informação, afrontando a expressão "Copright all rights reserved".

A ideia nasceu com o intuito de derrubar as muralhas do mercado e unir usuários de computadores, Stallman afirma que em 1984 "Era impossível usar um computador moderno sem a instalação de um sistema operacional proprietário". Isso o inquietava. Foi aí que sua luta teve início. A pretensão era de produzir um Sistema Operacional totalmente livre, que mais tarde ele nomearia de GNU:

O nome do sistema, GNU, é um acrônimo recursivo significando "GNU's Not Unix [GNU Não é Unix]", uma maneira de pagar o tributo ao Unix, enquanto ao mesmo tempo dizendo que GNU é algo diferente. Tecnicamente, GNU é como Unix. Mas diferentemente do Unix, GNU dá liberdade aos seus usuários (STALLMAN, 1999).

O usuário não precisará pagar pelo uso do produto, por permissões e nem dar satisfações, ele simplesmente usufrui livremente sem obstáculos financeiros ou "burocráticos". Se quiser modificar tudo, usar particularmente, distribuir gratuitamente ou vender, estará dentro da legalidade porque o programa é disponibilizado para seu uso irrestrito e indiscriminado. A liberdade defendida pelo 
Sanderli José da Silva Segundo; Wagner Junqueira de Araújo; Wendy-Anna Albuquerque Lopes

Projeto de layout de biblioteca assistido por ferramenta de software para criação de arranjo físico em 3D: estudo aplicado à biblioteca da faculdade Idez

movimento, dá direitos para que o usuário rode o programa como e onde quiser, estude e altere o código fonte como quiser, redistribua cópias exatas doando ou vendendo e distribua cópias da sua versão modificada sempre que possível.

As tecnologias da informação acentuam o individualismo porque produtos e serviços oferecidos são, cada vez mais, personalizados, enxergam o homem como indivíduo que é e ele, conforme foi dito, necessita de liberdade, mesmo que correntes sociais tendam à centralização. Nesse contexto, o usuário que mantém intimidade com as tecnologias da informação estará embasado para lutar por, e exercer sua "livre expressão". O portal Software Livre Brasil define como software livre:

Aquele que se refere à liberdade dos usuários executarem, copiarem, distribuírem, estudarem, modificarem e aperfeiçoarem o software. Mais precisamente, ele se refere a quatro liberdades para os usuários do software: A liberdade de executar o programa, para qualquer propósito; a liberdade de estudar como o programa funciona, e adaptá-lo para as suas necessidades; a liberdade de redistribuir cópias de modo que se possa ajudar ao próximo usuário; a liberdade de aperfeiçoar o programa, e liberar os seus aperfeiçoamentos, de modo que toda a comunidade se beneficie (STALLMAN, 2011).

Por outro lado existe um conjunto de ferramentas de software que não possuem a licença tipo GPL, mas permitem sua utilização de forma gratuita. Diferentes das ferramentas de software livre, estas não permitem a alteração do código, porém estão disponíveis para utilização sem custos, o que viabiliza sua aplicação. Esse direito ao conhecimento que Richard Stallman pregou como liberdade, ganhou muitos obstáculos e perseguição. Roubo e pirataria são nomes dos quais elegem para denunciá-lo, processos, propaganda contra, cerco policial em escritórios, viraram arma financiadas por empresas e governo contra o movimento do Software Livre. O criador enxerga isso como pura tentativa de manipular a massa:

Essa linha de persuasão não tem intenção de incentivar o pensamento crítico, mas sim de reforçar um hábito de pensamento [...]. Cada americano sabe que, há quarenta anos, era contra a lei em muitos estados uma pessoa negra sentar na frente num ônibus; mas apenas os racistas diriam que sentar lá era errado (STALLMAN, 2010). 
Sanderli José da Silva Segundo; Wagner Junqueira de Araújo; Wendy-Anna Albuquerque Lopes

Projeto de layout de biblioteca assistido por ferramenta de software para criação de arranjo físico em 3D: estudo aplicado à biblioteca da faculdade Idez

A questão levantada é se a informação é um bem comum ou propriedade de poucos? Por que uns produzem, outros usam e estes não têm acesso a todo o produto? O Software proprietário beneficia poucos em detrimento de muitos, é como andar para trás, enquanto a elite lidera usando suas próprias regras e formas de distribuição, excluindo aqueles que não podem pagar pelo uso e incriminando qualquer tipo de compartilhamento, impondo limites ferrenhos contra o real uso. Esses obstáculos à informação ferem o progresso e a inclusão social.

\subsection{Metodologia para Seleção de Software}

Dentre as atividades propostas neste projeto, está a que implica na seleção de determinadas ferramentas de software. Para isso, optou-se por aplicar um método multicritério de análise de decisão. Segundo Villas Boas (2010), "[...] os métodos multicritérios de análise de decisão (MMAD) aparecem como uma opção para consecução desse propósito. Eles proveem um maior entendimento do contexto multidisciplinar do processo decisório."

Os modelos de processos decisórios de problemas multicriteriais têm como finalidade apresentar uma lista ordenada das alternativas para solução de um problema, de acordo com as preferências dos decisores, ou selecionar, entre todas alternativas, a solução que melhor satisfaça os objetivos dos decisores (VILLAS BOAS, 2006).

Estas técnicas podem, por conseguinte, serem "utilizadas para: (a) identificar a melhor opção, (b) ordenar as opções, (c) listar um número limitado de alternativas para uma subsequente avaliação detalhada, ou (d) simplesmente distinguir as possibilidades aceitáveis das inaceitáveis" (VILLAS BOAS, 2006). Considerando os objetivos e definidos os critérios necessários para a solução do problema, é possível utilizar as técnicas de decisão multicritério para sua resolução. Os passos podem ser assim indicados: definição de pesos para os critérios, normalização e combinação dos critérios, onde são atribuídos pesos aos critérios identificados, que por sua vez podem ser tabulados por meio de software apropriado (GOMES, 1998; VILLAS BOAS, 2006). Para o propósito de trabalhar arranjos físicos em bibliotecas, é possível listar algumas ferramentas com tal funcionalidade. Para elaboração da 
Sanderli José da Silva Segundo; Wagner Junqueira de Araújo; Wendy-Anna Albuquerque Lopes

Projeto de layout de biblioteca assistido por ferramenta de software para criação de arranjo físico em 3D: estudo aplicado à biblioteca da faculdade Idez

Tabela 2, onde as ferramentas de software foram analisadas, utilizaram-se os seguintes critérios:

- Idioma: A ferramenta que possui interface em português é tida como fundamental para o projeto, uma vez que facilita a utilização por usuários iniciantes sem a necessidade de terem conhecimento de outro idioma. Portanto atribuiu-se 10 pontos para a língua portuguesa e 5 para interface em outros idiomas;

- Licença: Conforme a discussão já apresentada é desejável que a ferramenta tenha licença de acesso livre. Atribuiu-se para licenças do tipo GPL/GNU 10 pontos, para licenças gratuitas 7 pontos, para as demais tipos 3 pontos;

- Visualização 3D: A visualização em 3D fornece uma visão privilegiada do ambiente trabalhado, permite um dimensionamento mais próximo do original das formas e objetos, portanto aplicou-se 10 pontos para a ferramenta que disponibiliza Visualização 3D e 5 pontos para as demais;

- Biblioteca de Objetos: Foram atribuídos 10 pontos para a ferramenta que possui uma opção de integração de Biblioteca de Objetos em formatos abertos. E 5 pontos para as demais;

- Gera Fotos em 3D: Quando a intenção é registrar, publicar ou divulgar as propostas trabalhadas em um projeto, essa opção torna-se indispensável na apresentação do trabalho, por isso aplicou-se 10 pontos para esta funcionalidade e 0 para as demais;

- Gera Vídeos: A possibilidade de criar um vídeo, simulando uma visita virtual dentro do layout produzido, ajuda detectar possíveis falhas nos espaços de circulação do ambiente e também pode ser usado na divulgação e apresentação do projeto, visto que permite simular a movimentação de pessoas no novo ambiente, por isso aplicou-se 10 pontos para a ferramenta que gera fotos e 3 para os demais;

- Metadados: A possibilidade de incluir metadados nos arquivos produzidos facilita na busca e recuperação, pois permite um tipo de 
Sanderli José da Silva Segundo; Wagner Junqueira de Araújo; Wendy-Anna Albuquerque Lopes

Projeto de layout de biblioteca assistido por ferramenta de software para criação de arranjo físico em 3D: estudo aplicado à biblioteca da faculdade Idez

catalogação do arquivo, deste modo foi atribuído 10 pontos para os que possuem e 3 para os restante;

- Facilidade de Uso (Interatividade): Proporciona maior agilidade na criação, edição e execução de projetos, além de possuir funcionalidades intuitivas para iniciantes, por isso foi utilizado 10 pontos para designar os aplicativos que facilitam o uso e 3 para os que não o fazem.

A Tabela 1 apresenta o resultado da aplicação do método MMAD, sendo que o SH3D obteve a melhor pontuação:

Tabela 1 - Aplicações e Critérios.

\begin{tabular}{c|c|c|c|c|c|c|c|c|c}
\hline $\begin{array}{c}\text { Aplicações } \\
\text { e critérios }\end{array}$ & Idioma & $\begin{array}{c}\text { Tipo de } \\
\text { Licença }\end{array}$ & $\begin{array}{l}\text { Visualização } \\
\text { 3D }\end{array}$ & $\begin{array}{c}\text { Biblioteca } \\
\text { de objetos }\end{array}$ & $\begin{array}{c}\text { Gera } \\
\text { fotos }\end{array}$ & $\begin{array}{c}\text { Gera } \\
\text { vídeo }\end{array}$ & $\begin{array}{c}\text { Possui } \\
\text { Metadados }\end{array}$ & $\begin{array}{c}\text { Facilidade } \\
\text { de Uso }\end{array}$ & Pontos \\
\hline $\begin{array}{c}\text { AutoCAD } \\
\text { Freestyle } \\
\text { Technology }\end{array}$ & 10 & 3 & 10 & 5 & 0 & 3 & 10 & 3 & $\mathbf{5 4}$ \\
\hline $\begin{array}{c}\text { Chief } \\
\text { Architect X2 }\end{array}$ & 5 & 3 & 10 & 10 & 10 & 10 & 10 & 10 & $\mathbf{6 9}$ \\
\hline $\begin{array}{c}\text { Google } \\
\text { Sketchup } \\
\text { Pro }\end{array}$ & 10 & 7 & 10 & 10 & 10 & 10 & 10 & 3 & $\mathbf{7 0}$ \\
\hline $\begin{array}{c}\text { Space } \\
\text { Designer 3D }\end{array}$ & 5 & 10 & 10 & 10 & 10 & 3 & 10 & 10 & $\mathbf{6 8}$ \\
\hline $\begin{array}{c}\text { Sweet } \\
\text { (SH3D) }\end{array}$ & 10 & 10 & 10 & 10 & 10 & 10 & 10 & 10 & $\mathbf{9 0}$ \\
\hline
\end{tabular}

Fonte: Elaborado pelos autores.

O Quadro 2 indica a fonte de consulta para obtenção das ferramentas avaliadas, os idiomas suportados e o tipo de licença. Em parte das ferramentas, o tipo da licença de uso só pode ser verificado durante o processo de instalação.

Quadro 2 - Ferramentas para trabalhar Objetos 3D.

\begin{tabular}{llll}
\hline $\begin{array}{c}\text { Descrição } \\
\text { do }\end{array}$ & Idioma & $\begin{array}{l}\text { Tipo da } \\
\text { licença }\end{array}$ & Link para o site \\
software & & http://usa.autodesk.com/autocad/ \\
\hline $\begin{array}{l}\text { AutoCAD } \\
\text { Freestyle }\end{array}$ & Português & $\begin{array}{l}\text { Gratuito } \\
\text { para testar }\end{array}$ & \\
$\begin{array}{lll}\text { Technology } \\
\text { Chief }\end{array}$ & Inglês & Gratuito & http://www.chiefarchitect.com/ \\
\hline
\end{tabular}


Sanderli José da Silva Segundo; Wagner Junqueira de Araújo; Wendy-Anna Albuquerque Lopes

Projeto de layout de biblioteca assistido por ferramenta de software para criação de arranjo físico em 3D: estudo aplicado à biblioteca da faculdade Idez

\begin{tabular}{|c|c|c|c|}
\hline $\begin{array}{l}\text { Architect X2 } \\
\text { Google } \\
\text { Sketchup } \\
\text { Pro }\end{array}$ & Português & $\begin{array}{l}\text { para testar } \\
\text { Gratuito } \\
\text { para testar }\end{array}$ & http://sketchup.google.com/ \\
\hline $\begin{array}{l}\text { Space } \\
\text { Designer 3D }\end{array}$ & Inglês & Gratuito & http://www.spacedesigner3d.com/index.pt.php \\
\hline $\begin{array}{l}\text { Sweet Home } \\
\text { 3D (SH3D) }\end{array}$ & Português & Gratuito & http://www.sweethome3d.com/pt/index.jsp \\
\hline
\end{tabular}

3D (SH3D)

Fonte: Elaborado pelos autores.

Analisando o tipo de licença, as funcionalidades, plataformas suportadas, freqüência de atualizações, bibliotecas de objetos e idiomas optamos por trabalhar com o Sweet Home 3D (SH3D) que é uma aplicação de design interior que auxilia na criação de layout em plano 2D e visualizações em plano 3D (fonte http://www.sweethome3d.com/pt/index.jsp). O software foi publicado na internet no dia 16 de Novembro de 2006, na versão 0.10. Suas atualizações são ininterruptas, mensalmente os desenvolvedores acrescentam mais informações, a versão 3.2.1, foi a última atualização lançada dia 3 de maio de 2011. É distribuído sob a licença GPL e pode ser baixado no próprio site para posterior instalação ou acessado online através do navegador de internet. Está disponível em quinze idiomas, dentre eles o português. Além das atualizações constantes, o site conta com diversas utilidades que explicam como utilizar o SH3D e também oferecem subsídios para a criação dos layouts.

\section{DESENVOLVIMENTO DE PROJETO DE ARRANJO FísICO AUXILIADO PELO SH3D}

Conforme indicado na literatura e verificado na disciplina de Organização, Sistemas e Métodos, uma das opções para se trabalhar o arranjo físico de um ambiente organizacional, é pelo estudo de seu layout. Segundo Cury (2000), layout "[...] corresponde ao arranjo de diversos postos de trabalho nos espaços existentes na organização, envolvendo, além da preocupação de melhor adaptar as pessoas ao meio ambiente [...] a arrumação dos móveis, máquinas, equipamentos e matérias-primas". Já Araújo (2001), afirma que "O arranjo físico adequado proporciona a empresa maior economia e produtividade, com base na boa disposição dos instrumentos de trabalho". Entendemos que a função do layout é aproveitar ao máximo todas as funcionalidades que um setor pode desenvolver, 
Sanderli José da Silva Segundo; Wagner Junqueira de Araújo; Wendy-Anna Albuquerque Lopes

Projeto de layout de biblioteca assistido por ferramenta de software para criação de arranjo físico em 3D: estudo aplicado à biblioteca da faculdade Idez

levando em consideração seus recursos e espaço de trabalho. Ele viabiliza a amostra do ambiente em diversos ângulos, o que auxilia na idealização da nova alocação de recursos, sem contar que é muito mais fácil arrastar a mobília na tela do computador e achar a nova coerência nas disposições do que fazer isso fisicamente. Segundo os autores (CURY, 2000; ARAÚJO, 2001) os objetivos de um projeto de layout são apresentados no quadro 3:

Quadro 3 - Objetivos do Arranjo Físico

\begin{tabular}{|c|c|}
\hline Cury (2000) & Araújo (2001) \\
\hline $\begin{array}{l}\text { - Otimizar as condições de trabalho } \\
\text { pessoal nas nersas } \\
\text { organizacionais; } \\
\text { - Racionalizar os fluxos de fabricação } \\
\text { ou de tramitação de processos; } \\
\text { - Racionalizar a disposição física dos } \\
\text { postos de trabalho, aproveitando todo o } \\
\text { espaço útil disponível; } \\
\text { - Minimizar a movimentação de } \\
\text { pessoas, produtos, materiais e documentos } \\
\text { dentro da ambiência organizacional. }\end{array}$ & 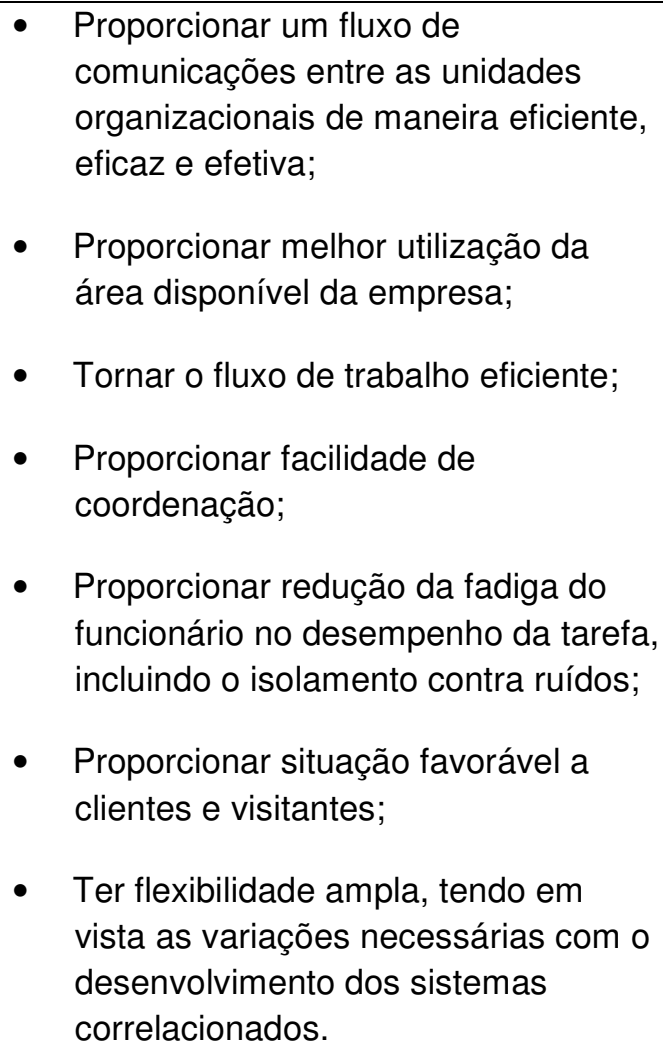 \\
\hline
\end{tabular}

Fonte: Adaptado de Cury (2000), Araújo (2001) e Oliveira (2006).

O SH3D permite o desenvolvimento de projetos de layouts em escala real, com visualizações em 2D enfatizando a noção de espaço usado e livre, e 3D oferecendo a possibilidade de entrar na biblioteca virtual e caminhar pelos seus corredores, serviços, salas. Possibilita, portanto, observar de perto todas as mudanças desejadas permitindo um planejamento coerente no uso do espaço, mobília e circulação. A linha de criação dá condições para formar paredes, cores, pisos, portas, janelas, móveis, quartos, dimensões, legendas, importar imagens de 
Sanderli José da Silva Segundo; Wagner Junqueira de Araújo; Wendy-Anna Albuquerque Lopes

Projeto de layout de biblioteca assistido por ferramenta de software para criação de arranjo físico em 3D: estudo aplicado à biblioteca da faculdade Idez

fundo, importar mobília, modificar tamanho tanto da construção quanto dos móveis, objetos e personagens, e editar tudo o que for criado. Na construção do projeto é possível gerar fotos do layout em suas dimensões e ângulos diversos, possui funções para exportar a foto no formato PNG, permite criar vídeos simulando o transitando pelo ambiente na visão de um usuário comum. Conforme indicado no quadro 4:

Quadro 4 - Funcionalidades do Sweet Home 3D.

\begin{tabular}{|c|c|}
\hline MENU & Função \\
\hline$\square$ & Criar uma nova casa. \\
\hline 鸟 & Abre uma casa. \\
\hline 8 & Salva a casa. \\
\hline 策 & Adicionar mobília selecionada no catalogo na casa. \\
\hline 中 & Selecionar objetos no plano. \\
\hline sing & Arrastar no plano. \\
\hline+ & Criar paredes. \\
\hline 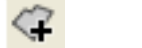 & Criar quartos. \\
\hline $2 \times$ & Criar dimensões. \\
\hline$A_{+}$ & Adicionar textos. \\
\hline A & Aumentar tamanho dos textos selecionados. \\
\hline$\Delta$ & Diminuir tamanho dos textos selecionados. \\
\hline$\Delta$ & Negrito \\
\hline Д & Itálico \\
\hline \&. 8 & Ferramentas de zoom (aumentar e diminuir). \\
\hline 㝵 & Criar foto da visão 3D. \\
\hline वृ & Criar um vídeo 3D. \\
\hline
\end{tabular}

Fonte: Elaborado pelos autores. 
Sanderli José da Silva Segundo; Wagner Junqueira de Araújo; Wendy-Anna Albuquerque Lopes

Projeto de layout de biblioteca assistido por ferramenta de software para criação de arranjo físico em 3D: estudo aplicado à biblioteca da faculdade Idez

O portal do SH3D possui ferramentas de suporte aos clientes como o FAQ (área de perguntas frequentes), tutoriais em vídeo, manuais e uma grande biblioteca de modelos 3D de objetos como mobília, pessoas, veículos, prédios, animais e etc., além de disponibilizar links de outros sites que possuem outras bibliotecas de objetos.

\section{$5 \quad$ APLICAÇÃO DO SH3D NO PROJETO DE BIBLIOTECA}

O resultado da aplicação da ferramenta de software no projeto de layout que possibilitou mudanças significativas na Biblioteca da Faculdade iDEZ. Em seu antigo formato, um grande balcão fazia separação entre livros e usuários (Figura 1), a 1a sala de estudo individual estava inacessível, pois servia como uma espécie de arquivo da secretaria (Figura 2), a sala de estudo em grupo não funcionava por falta de cadeiras e mesa (Figura 2), as mesas individuais de estudo ocupavam um espaço desnecessário, que dificultava o acesso para as salas de estudo (Figura 2). Visualizado nas seguintes figuras:

Figura 1 - Fluxo congestionado no atendimento.

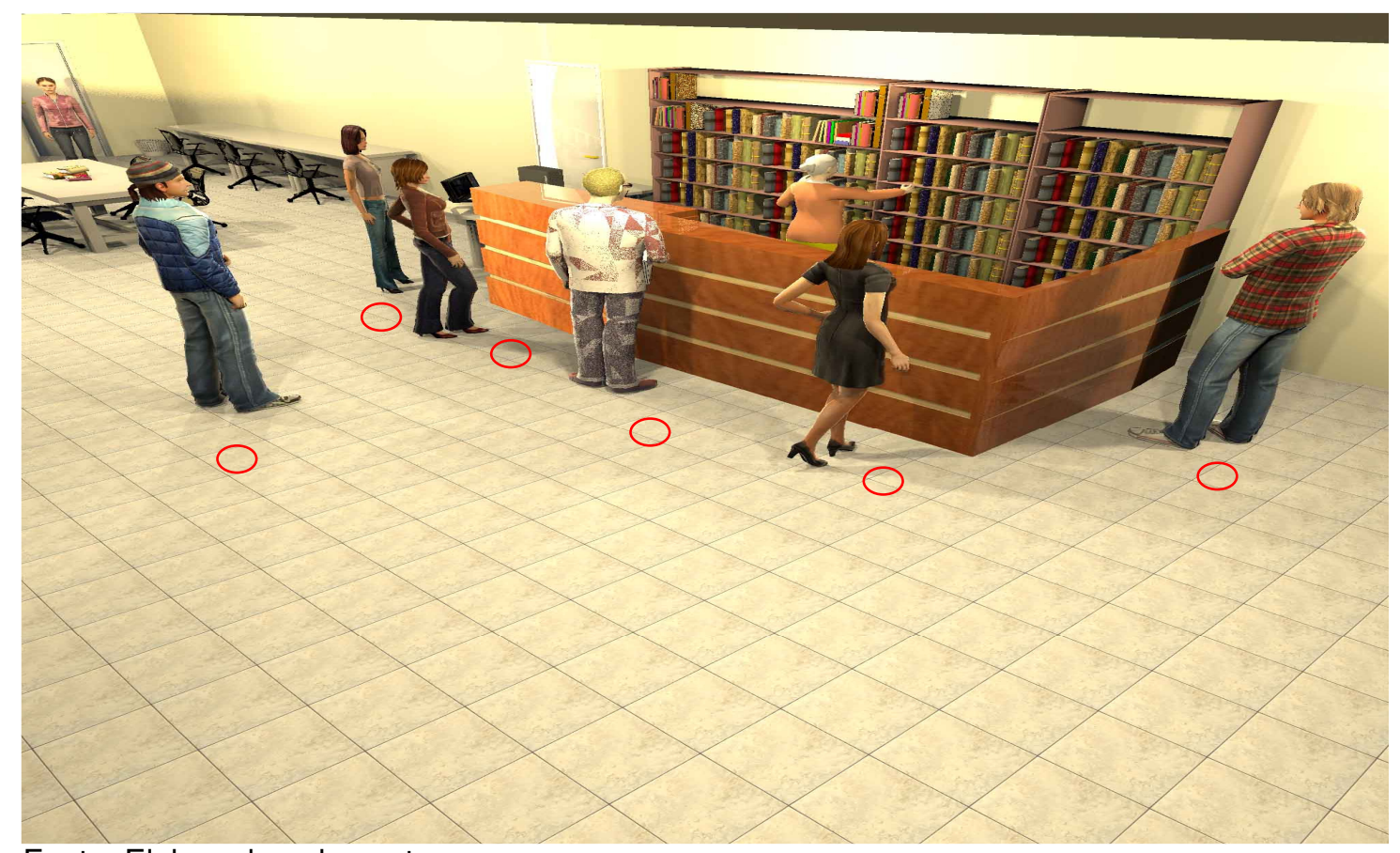

Fonte: Elaborado pelos autores.

Inf. Inf., Londrina, v. 18, n.1, p. $184-205$, jan./abr. 2013. http:www.uel.br/revistas/informacao/ 
Sanderli José da Silva Segundo; Wagner Junqueira de Araújo; Wendy-Anna Albuquerque Lopes

Projeto de layout de biblioteca assistido por ferramenta de software para criação de arranjo físico em 3D: estudo aplicado à biblioteca da faculdade Idez

Figura 2 - Visão Geral do Antigo Layout.

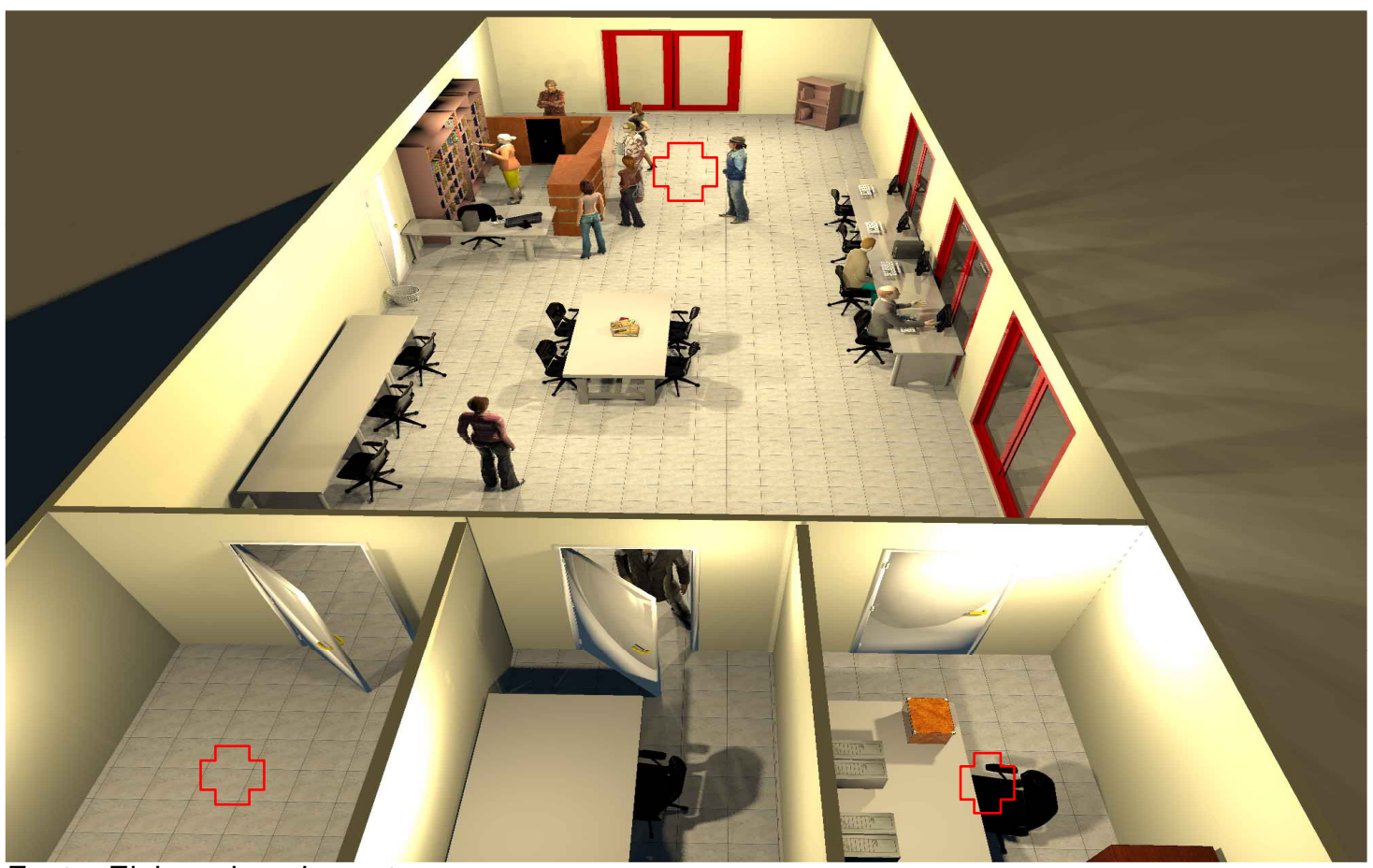

Fonte: Elaborado pelos autores.

O fluxo informacional era congestionado, principalmente porque a biblioteca funcionava ainda nos conceitos de posse e armazenamento do acervo, conforme indicação da "Figura 1". O projeto possibilitou visualizar um modelo de arranjo que utilizasse estantes soltas organizadas em simetria e linha reta, oferecendo liberdade de manuseio dos livros aos usuários (Figura 3); Foi retirado o arquivo da secretaria na $1^{\underline{a}}$ sala individual de estudo (Figura 4); A sala coletiva de estudo foi mobiliada; E decidiu-se integrar as mesas individuais de estudo com as dos computadores, seguindo uma linha reta, permitindo o aproveitamento do espaço vago da parede em branco para expor trabalhos acadêmicos dos alunos da faculdade e avisos para os mesmos (Figura 4); Os vãos de circulação foram ampliados, liberando um grande tráfego de alunos (Figura 4); Os serviços mesmo sendo interligados agora mantém uma distância significativa, o espaço destinado a uma tarefa não interfere nas outras, conforme indicado por Cury (2000), Araújo (2001) e Oliveira (2006); Diversos corredores de circulação foram criados, só entre as estantes são sete, quatro horizontais e três verticais, na nave da biblioteca são três verticais e dois horizontais. Conforme as seguintes figuras: 
Sanderli José da Silva Segundo; Wagner Junqueira de Araújo; Wendy-Anna Albuquerque Lopes

Projeto de layout de biblioteca assistido por ferramenta de software para criação de arranjo físico em 3D: estudo aplicado à biblioteca da faculdade Idez

Figura 3 - Estantes (nova disposição).

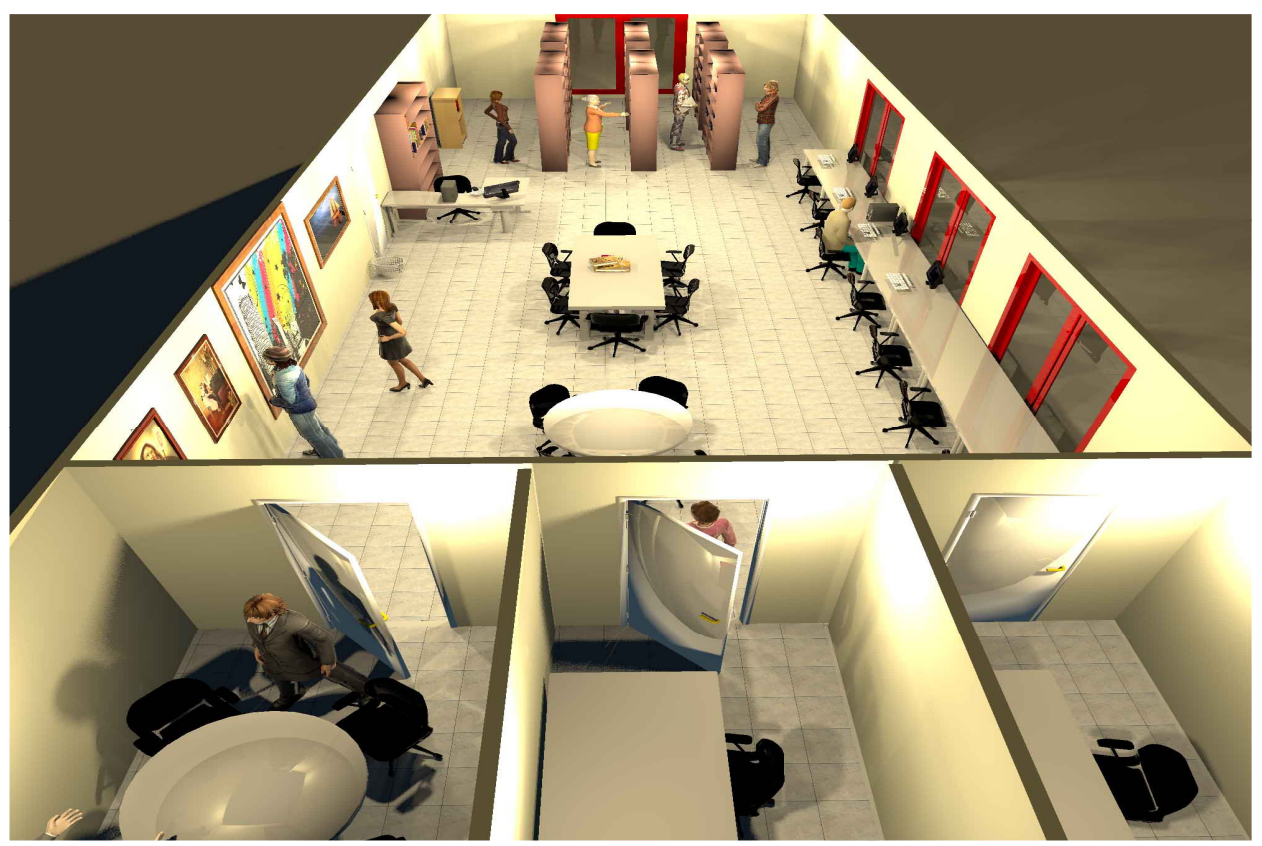

Fonte: Elaborado pelos autores.

Figura 4 - Visão Geral do Novo Layout.

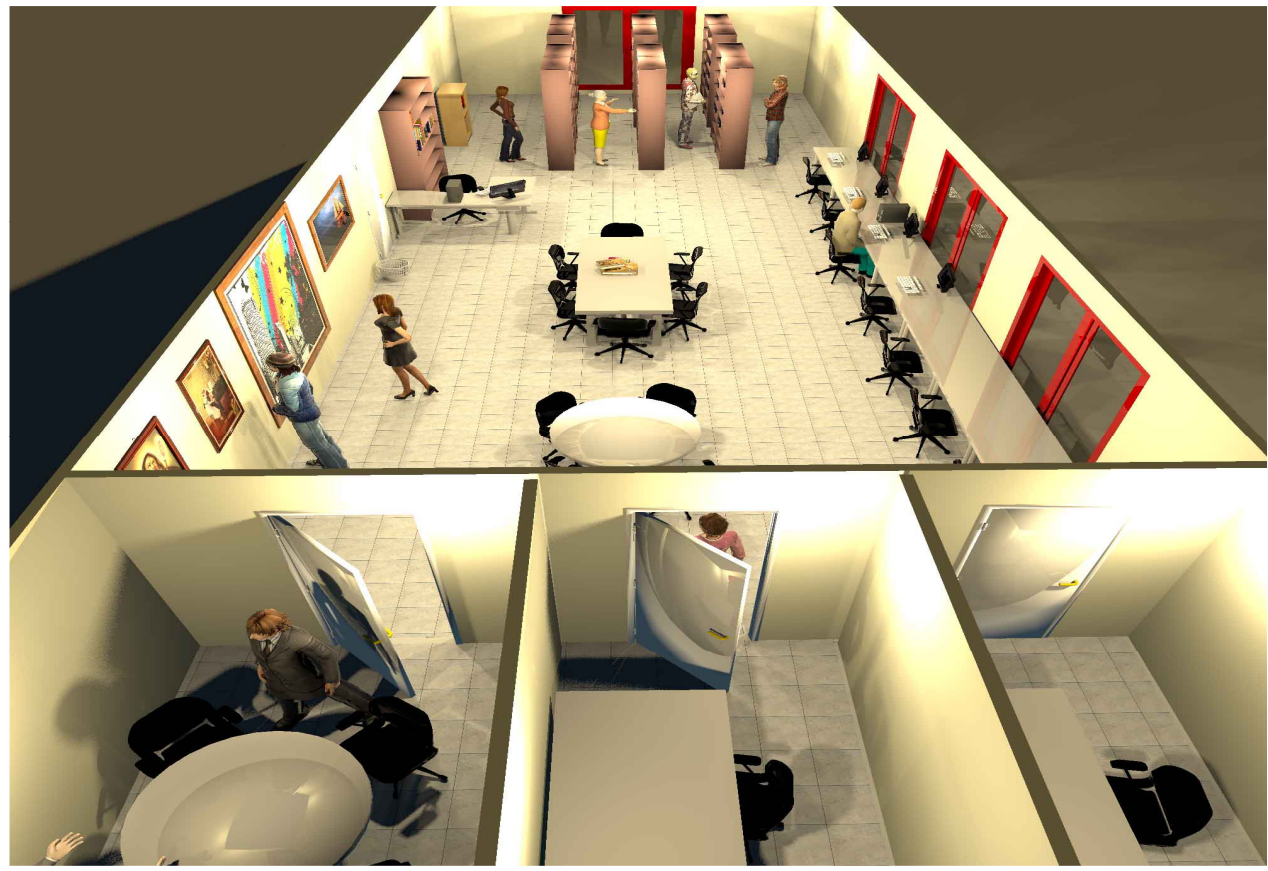

Fonte: Elaborado pelos autores.

No desenvolvimento deste projeto procuramos economizar esforços dos usuários em obter os serviços desejados, ao adotarmos um padrão de fluxo informacional mais próximo possível da linha reta, conforme descrito por Cury (2000) e Oliveira (2006), atendendo dessa forma os três primeiros objetivos do projeto. 
Sanderli José da Silva Segundo; Wagner Junqueira de Araújo; Wendy-Anna Albuquerque Lopes

Projeto de layout de biblioteca assistido por ferramenta de software para criação de arranjo físico em 3D: estudo aplicado à biblioteca da faculdade Idez

Assim que o usuário entra no ambiente encontra o bibliotecário, podendo tirar ou não suas primeiras dúvidas. No seu lado esquerdo estará o acervo, se ele decidir procurar algum livro, escolhido o exemplar, o usuário irá olhar para o lado direito da biblioteca, constatará ao menos cinco possibilidades básicas: usar os computadores para algum fim, sentar nas mesas de estudo em grupo, sentar nas mesas de estudo individual, entrar em uma das duas cabines de estudo individual, na cabine de estudo coletivo ou fazer o empréstimo e sair. Esta configuração de layout pode ser observada na Figura n 5, nº 6 e no Youtube, com o título "Biblioteca iDEZ: Projeto de Melhoria de Layout/Agosto 2011 através do link "http://www.youtube.com/watch?v=Ozi8Vtdo0Mc".

Figura 5 - Configuração em linha reta.

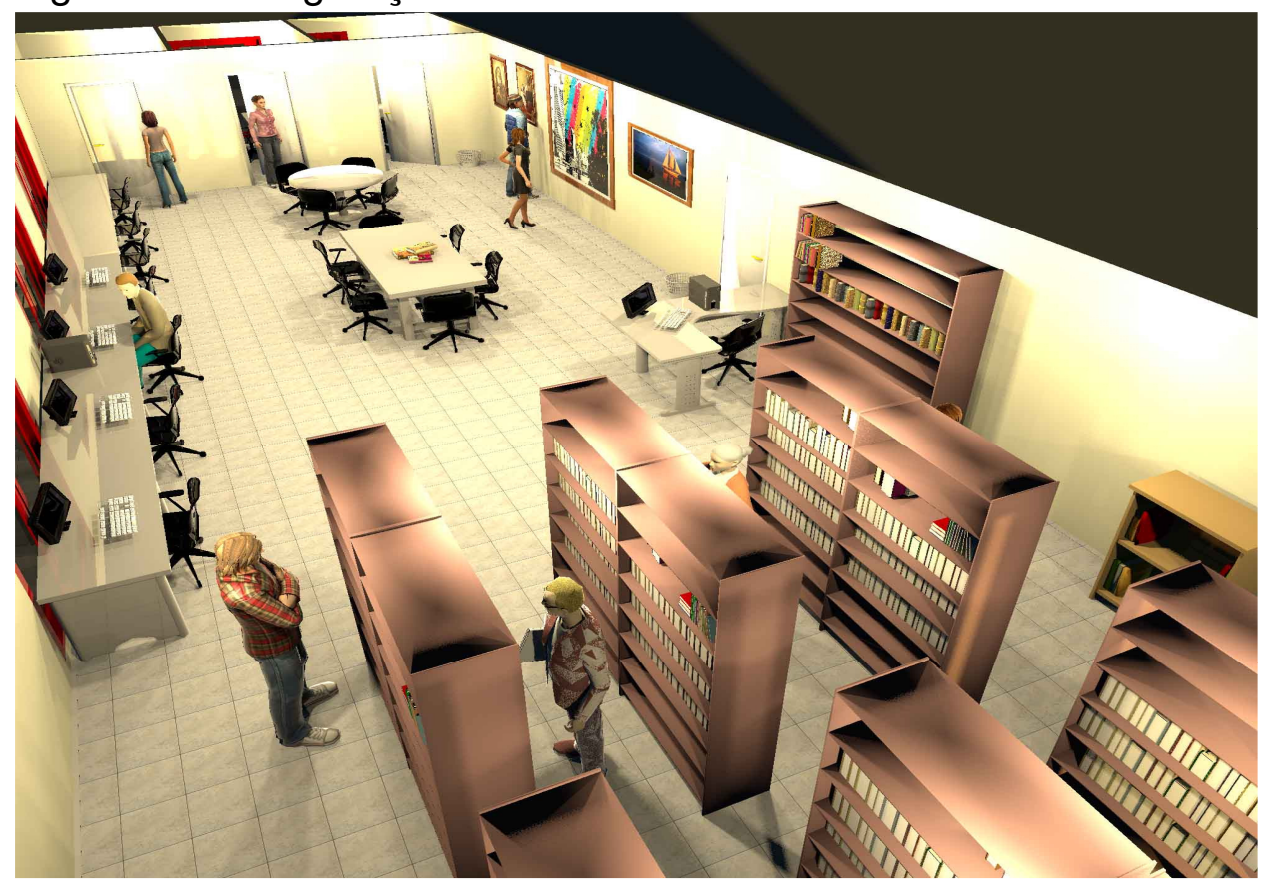

Fonte: Elaborado pelos autores. 
Sanderli José da Silva Segundo; Wagner Junqueira de Araújo; Wendy-Anna Albuquerque Lopes

Projeto de layout de biblioteca assistido por ferramenta de software para criação de arranjo físico em 3D: estudo aplicado à biblioteca da faculdade Idez

Figura 6 - Vista aérea do resultado do projeto.
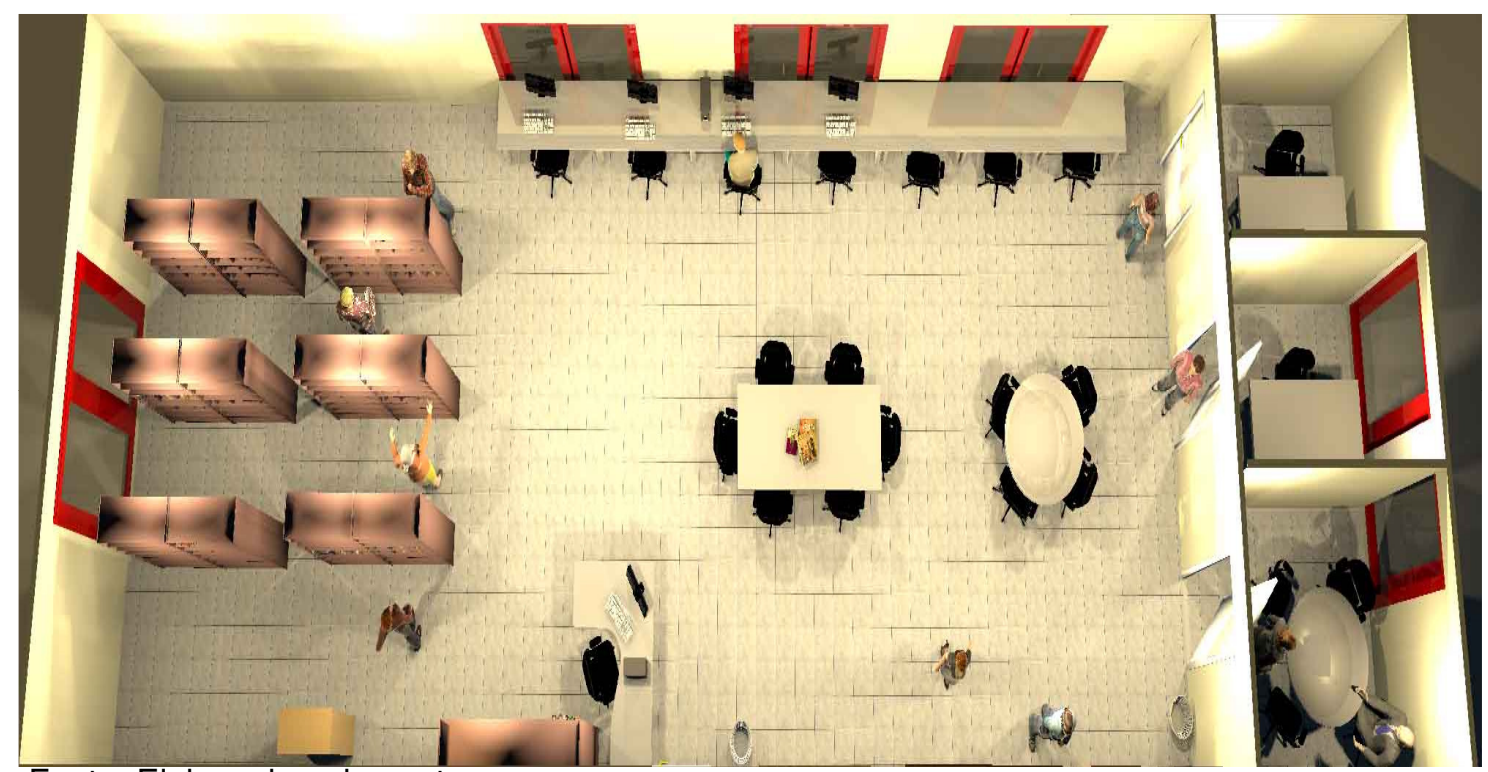

Fonte: Elaborado pelos autores.

\section{CONSIDERAÇÕES FINAIS}

Através do estudo realizado, verificou-se que o software livre SH3D obteve a melhor pontuação em relação aos critérios propostos e adequada para projetos de layout, disponibiliza gratuitamente suas funcionalidades, constatou-se seu potencial de aplicação por gestores de Bibliotecas que não dispõem de recursos financeiros suficientes para investir em softwares proprietários. Além disso, conforme especificações das licenças GPL, tal programa de computador está aberto para qualquer modificação que os seus usuários achem pertinentes e permite suas redistribuições. Constatou-se que os princípios de Organização, Sistemas e Métodos (OS\&M) para arranjo físico (layout) podem ser aplicados em um ambiente de biblioteca, auxiliando na identificação de problemas, no fluxo de informação e de pessoas e na construção de justificativas. Contudo a contribuição do SH3D foi valorosa, pois conforme relato dos bibliotecários da iDez, sua aplicação foi fundamental no processo de convencimento da alta administração da Faculdade, ao indicar que a biblioteca necessitava passar por aprimoramentos em seu arranjo físico, com a finalidade de tornar o ambiente agradável, acessível e eficiente na disseminação da informação. No $2^{\circ}$ período letivo do ano de 2009 , o projeto foi aprovado e expedida a autorização de compra das estantes, livros e materiais 
Sanderli José da Silva Segundo; Wagner Junqueira de Araújo; Wendy-Anna Albuquerque Lopes

Projeto de layout de biblioteca assistido por ferramenta de software para criação de arranjo físico em 3D: estudo aplicado à biblioteca da faculdade Idez

administrativos que suprissem as novas atividades. Concluindo com êxito todos os objetivos propostos para esse projeto.

\section{REFERÊNCIAS}

ARAÚJO, Luis César G. Organização sistemas e métodos. São Paulo: Atlas, 2001.

COPYLEFT. In: WIKIPÉDIA. 2011. Disponível em:

<http://pt.wikipedia.org/wiki/Copyleft>. Acesso em: 10 jul. 2011.

CURY, Antônio. Organização e métodos: uma visão holística. 7. ed. São Paulo: Atlas. 2000.

FAYOL, H. Administração industrial e geral. Tradução de Irene de Bojano e Mário de Sousa. 3. ed. São Paulo: Atlas, 1958. Título original: Administration industrielle et générale.

FERREIRA, Francisco Whitacker. Planejamento: sim e não. 4. ed. Rio de Janeiro: Paz e Terra, 1983.

GNU GENERAL PUBLIC LICENSE. In: WIKIPÉDIA. 2011. Disponível em: $<$ http://pt.wikipedia.org/wiki/GNU_General_Public_License>. Acesso em: 10 jul. 2011.

GOMES, Luiz Flavio Autran Monteiro. Da informação à tomada de decisão: agregando valor através dos métodos multicritério. Recitec: Revista de ciência e tecnologia, Recife, v. 2, n. 2, p. 117-139, 1998.

MACIEL, Alba Costa; MENDONÇA, Marília Alvarenga Rocha. Bibliotecas como organizações. Rio de Janeiro: Interciência, 2000.

NASCIMENTO, Cecília Pereira et al. Planejamento estratégico em bibliotecas universitárias. In: SEMINÁRIO NACIONAL DE BIBLIOTECAS UNIVERSITÁRIAS, 11., 2000, Florianópolis. Anais... Florianópolis, 2000. CD-ROM.

OLIVEIRA, Djalma de Pinho Rebouças. Sistemas, organização e métodos: uma abordagem gerencial. São Paulo: Atlas, 2006.

STALLMAN, Richard. 15 Anos de software livre. 1999. Disponível em: <http://www.dominiopublico.gov.br/download/texto/tl000002.pdf>. Acesso em: 10 jul. 2011.

Porque softwere livre. 2010. Disponível em:

<http://wiki.nosdigitais.teia.org.br/Por_que_Software_Livre\%3F_-

_Richard_Stallman>. Acesso em: 10 jul. 2011. 
Sanderli José da Silva Segundo; Wagner Junqueira de Araújo; Wendy-Anna Albuquerque Lopes

Projeto de layout de biblioteca assistido por ferramenta de software para criação de arranjo físico em 3D: estudo aplicado à biblioteca da faculdade Idez

Software livre Brasil. Disponível em: <http://softwarelivre.org/softwarelivre>. Acesso em: 9 ago. 2011.

VILLAS BOAS, Cíntia de Lima. Método multicritérios de análise de decisão (MMAD) para as decisões relacionadas ao uso múltiplo de reservatórios: Analytic Hierarchy Process (AHP). Disponível em:

<http://www.cprm.gov.br/rehi/simposio/go/METODO\%20MULTICRITERIOS\%20DE\% 20ANALISE\%20DE\%20DECISAO\%20(MMAD)\%20PARA\%20AS\%20DECISOES\%2 ORELACIONADAS\%20AO\%20USO\%20MULTIPLO\%20.pdf>. Acesso em: 17 abr. 2010.

Modelo multicritérios de apoio à decisão aplicado ao uso múltiplo de reservatórios: estudo da barragem do Ribeirão João Leite. 2006. 158 f. Dissertação (Mestrado em Economia-Gestão Econômica do Meio Ambiente) - Departamento de Economia, Universidade de Brasília, Brasília. 2006

Title

Design layout of library aided software tool for the development of physical arrangement in 3D: applied to study iDEZ college library

\section{Abstract}

Introduction: To design a library involves efforts to create or improve several services that are consistent with the library's role and objectives as well as aims of organization that the library is inserted. Regularly managers of the different types of libraries are confronted with the problem of managing their physical space. The study of the layout can provide new ways to modify the space in order to get the requirements cited. However, to make modifications in the real situations is a challenge, this way a tool that allows the librarian, create, modify and view the results in 3D formats is of great help.

Objective: To study the physical layout of libraries from the perspective of OS\&M using 3D tools.

Methodology: Experimental study developed based on a case study in the library of the Faculty IDEZ, located in João Pessoa - PB, where it was applied the principles of the discipline of Organization, Systems and Methods (OS\&M) for physical layout using an open source tool to help projects in 3D.

Results: Are showed and discussed the motivations which lead an information professional to have to manage your space and barriers encountered. The results obtained in the evaluation showed the Sweet Home 3D as a tool with best score.

Conclusions: The project proposal resulting from the case study, improved visualization of the changes were accepted and carried out by the managers of the library.

Keywords: Information. Technology and communication. Library design. Open source software. Physical layout. Layout 3D. 
Sanderli José da Silva Segundo; Wagner Junqueira de Araújo; Wendy-Anna Albuquerque Lopes

Projeto de layout de biblioteca assistido por ferramenta de software para criação de arranjo físico em 3D: estudo aplicado à biblioteca da faculdade Idez

\section{Título}

Proyecto de layout de biblioteca asistido por herramienta de software para creación de arreglo físico em 3D: estudio aplicado a la biblioteca de la facultad iDEZ

\section{Resumen}

Introducción: Proyectar una biblioteca consiste en concentrar esfuerzos para crear o perfeccionar actividades de acuerdo con la función y objetivos de dicha biblioteca y de la institución a la que esté subordinada. Regularmente los administradores de los diferentes tipos de bibliotecas se enfrentan con el problema de la gestión de su espacio físico. El estudio del layout proporciona experimentar nuevas formas y permite hacer modificaciones de ambientación con el intuito de buscar los requisitos citados. No obstante, hacer todo eso en un entorno real, no siempre es posible, en estos casos, una herramienta que permita al bibliotecario proyectar, promover alteraciones y visualizar los resultados en 3D es muy útil.

Objetivo: Estudiar la disposición de las bibliotecas de la OS\&M perspectiva utilizando herramientas 3D.

Metodología: Este artículo presenta los resultados de un estudio experimental desarrollado a partir de un estudio de caso en la biblioteca de la Facultad iDEZ, ubicada en João Pessoa - PB, donde se aplican los principios de la disciplina de la Organización, Sistemas y Métodos (OS \& M) para disposición física (layout), utilizando una herramienta de código abierto para ayudar la realización de proyectos en tercera dimensión.

Resultados: Se presentaron y se discutieron las motivaciones que llevan un profesional de la información a tener que administrar su espacio y barreras encontradas. Los resultados obtenidos en la evaluación mostraron que el Sweet Home 3D como una herramienta con la mejor puntuación.

Conclusiones: La propuesta de proyecto resultante del estudio de caso, la mejora de la visualización de los cambios que se han aceptado y llevado a cabo por los responsables de la biblioteca.

Palabras clave: Tecnología de la información e comunicación. Proyecto de biblioteca. Software libre. Arreglo físico. Layout 3D.

Recebido em: 10.10.2011

Aceito em: 10.05.2013 